\title{
STUDYING A MASONRY SAIL VAULT BY ANTONIO DA SANGALLO THE ELDER IN THE FORTEZZA VECCHIA IN LIVORNO
}

\author{
F. BARSI $^{1}{ }^{*}$, D. AITA ${ }^{1}$, R. BARSOTTI ${ }^{1}$, D. ULIVIERI ${ }^{2}$ AND S. BENNATI $^{1}$ \\ ${ }^{1}$ Department of Civil and Industrial Engineering \\ University of Pisa \\ Largo Lucio Lazzarino 2, 56126 Pisa, Italy \\ e-mail: francescobarsi@gmail.com,danila.aita@unipi.it, r.barsotti@ing.unipi.it, \\ bennati.stefano@gmail.com \\ ${ }^{2}$ Department of Energy, Systems, Territory and Construction Engineering \\ University of Pisa \\ Largo Lucio Lazzarino 2, 56126 Pisa, Italy \\ e-mail: denise.ulivieri@unipi.it
}

Keywords: Masonry sail vault, Limit analysis, Durand-Claye's method.

\begin{abstract}
The present contribution aims to illustrate some first results obtained from ongoing research on a 16th-century masonry sail vault in the Fortezza Vecchia (the Old Fortress) in Livorno (Italy). A multidisciplinary research is currently ongoing. The information collected by means of geometric surveys and experimental tests are being used as input data for the different analytical and numerical models expressly developed to study the vault's structural response. The structural analysis has been performed using two analytical models set within the framework of limit analysis. The first considers the vault as a thin shell, and suitable sets of statically admissible stresses are built; the second model is a modern reinterpretation of Durand-Claye's method for domes. As an additional term of comparison, numerical analyses are carried out by means of FE models. The study is still under development, and a first set of results has been obtained by limiting the analysis to vertical loads accounting for the self-weight of the vault and that of the overlying soil layers.
\end{abstract}

\section{INTRODUCTION}

The present contribution aims at illustrating a preliminary study of the mechanical response of a subterranean sail vault covering a quadrilateral room located in the Canaviglia bastion of the Fortezza Vecchia (the Old Fortress) in Livorno. The Fortezza Vecchia is a maritime castle of great historical interest representative of 15th- and 16th- century Tuscan architecture, built on behalf of the Florentine government. The study is framed within a research project (PRA 2017 - "Tuscan Renaissance architecture: case studies between historical investigation, survey and structural analysis"), promoted by the University of Pisa. Some results obtained in the first phase of the research are illustrated in [1-2]. 


\section{THE "FORTEZZA VECCHIA" IN LIVORNO}

The Fortezza Vecchia (Old Fortress) in Livorno is one of the most significant "alla moderna" military garrisons in Tuscany. Pisa and later Firenze choose this site located on the sea at the eastern end of Livorno as a management center for port activities.

Between 1369 and 1376 the "Rocca Nuova" was built, then called "Quadratura dei Pisani". In 1421 Florence purchased Livorno for 100,000 gold florins, while Pisa, already sold to Florence in 1405, strongly opposed the Florentine domination. Livorno became "la pupilla dell'occhio del dominio Fiorentino" (the pupil of the eye of the Florentine dominion) [3, p. 69] and began to fortify.

In 1506, Antonio da Sangallo the Elder (c. 1455-1534) arrives in Livorno. As chronicled by Giorgio Vasari, Antonio da Sangallo's drawing of the Livorno Fortress was not "entirely executed, nor in the way Antonio had drawn it" [4, IV, p. 288]. The Livorno citadel is a work stylistically similar to that in Pisa, on which Antonio began work in 1509. However, in August of the same year management of the site was taken over by Giuliano, who drew up the final plans [5, p. 685]. At the Livorno construction site, several engineers, technicians and experts oversaw the various stages of construction.

The Livorno Fortress contains some imposing medieval buildings - the Square Tower, the Keep, the Quadratura dei Pisani. Medieval tradition played a considerable role in the drafting of the plans for Livorno. The layout of the Livorno fort was not geometrically regular because of the massive medieval structures it incorporated, and its peculiar position completely

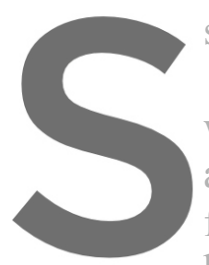
surrounded by the sea

As early as 1519 ' work began on the new and later still Caviniglia. As the foundations formwork was made, though not without diffic became an island reachable from land by a boat pulled by cab
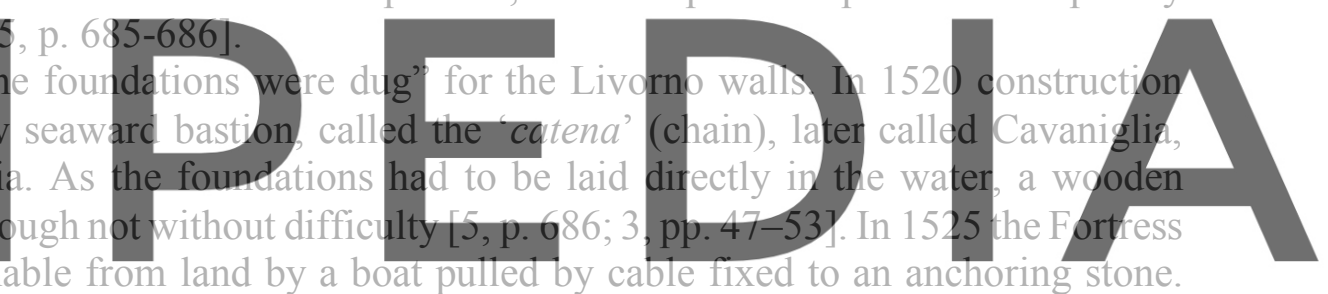
Between 1546 and 1547, Cosimo I de' Medici, decided to build a palace for his family right medieval Keep [6].

\section{THE SAIL VAULT BY ANTONIO DA SANGALLO THE ELDER IN THE CANAVIGLIA BASTION OF THE FORTEZZA VECCHIA}

The contour of the Canaviglia bastion is very wide; the throat instead contains the facades of both the quadrangular medieval tower and the contiguous corner of the Quadratura. The west flank is connected to the corner of the Quadratura dei Pisani, which works as the seaward curtain, by a short stretch of wall 16 cubits long. This section contains the inspired addition of an unusual trapezoidal room, covered by a sail vault with an octagonal central ventilation oculus, which links the concave retired flank with the square tower and the medieval stronghold (Figure 1). This room represents a structure of great interest, in which we can recognize the Sangallo brothers' research into "ancient spatial concepts filtered and mediated by Brunelleschi's inventions" [5, p. 688].

The data collected via a TLS survey of the entire fortress (inside and out) has been made available by the administrative bodies (Autorità di Sistema Portuale del Mar Tirreno 
Settentrionale - North Tyrrhenian Sea Port Authority). The survey, available as a point cloud, features a density of about 3 points per square centimeter. The point clouds were recorded in a single reference system and were furnished in Autodesk ReCap format. The Autodesk environment made it easy to extract the geometries needed for structural analysis.

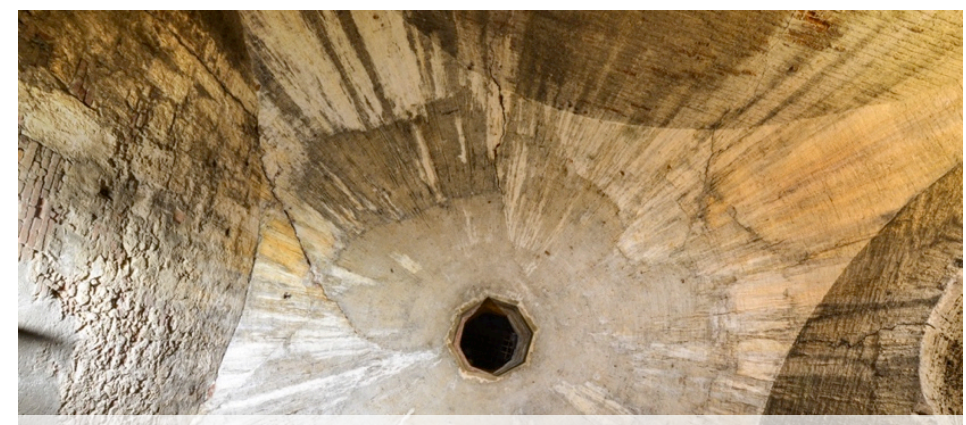

Figure 1: Canaviglia bastion, trapezoidal room covered by a sail vault with octagonal central oculus. Image by Photographic Laboratory, Department of Civilizations and Forms of Knowledge, University of Pisa.
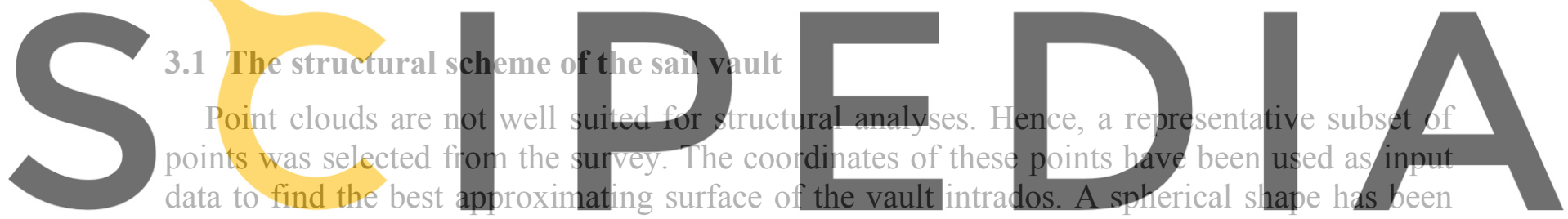

chosen a priori as approximating surface. The search for the optimal parameters values has been

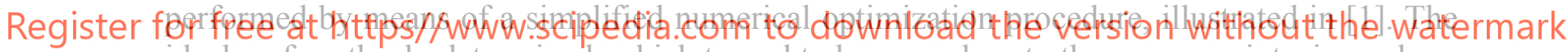
ideal surface thusly determined, which turned to be very close to the survey points, is a sphere of 5.5-meter radius.

The vault thickness has been estimated by means of the results of the still ongoing experimental campaign. More precisely, the internal stratigraphy of the vault was investigated by performing 16 endoscopic tests which enabled verifying that the vault is made of seemingly uniform brick masonry. The vault thickness is minimum at the top, where it is equal to $50 \mathrm{~cm}$, and gradually increases as the vault approaches the lateral walls. In order to build a simple structural scheme of the vault that is on the safe side, a uniform thickness of $50 \mathrm{~cm}$ has been adopted in the analyses for the resisting part of the vault (Figure 2). The part of the vault that exceeds $50 \mathrm{~cm}$ has been considered as a dead load. 

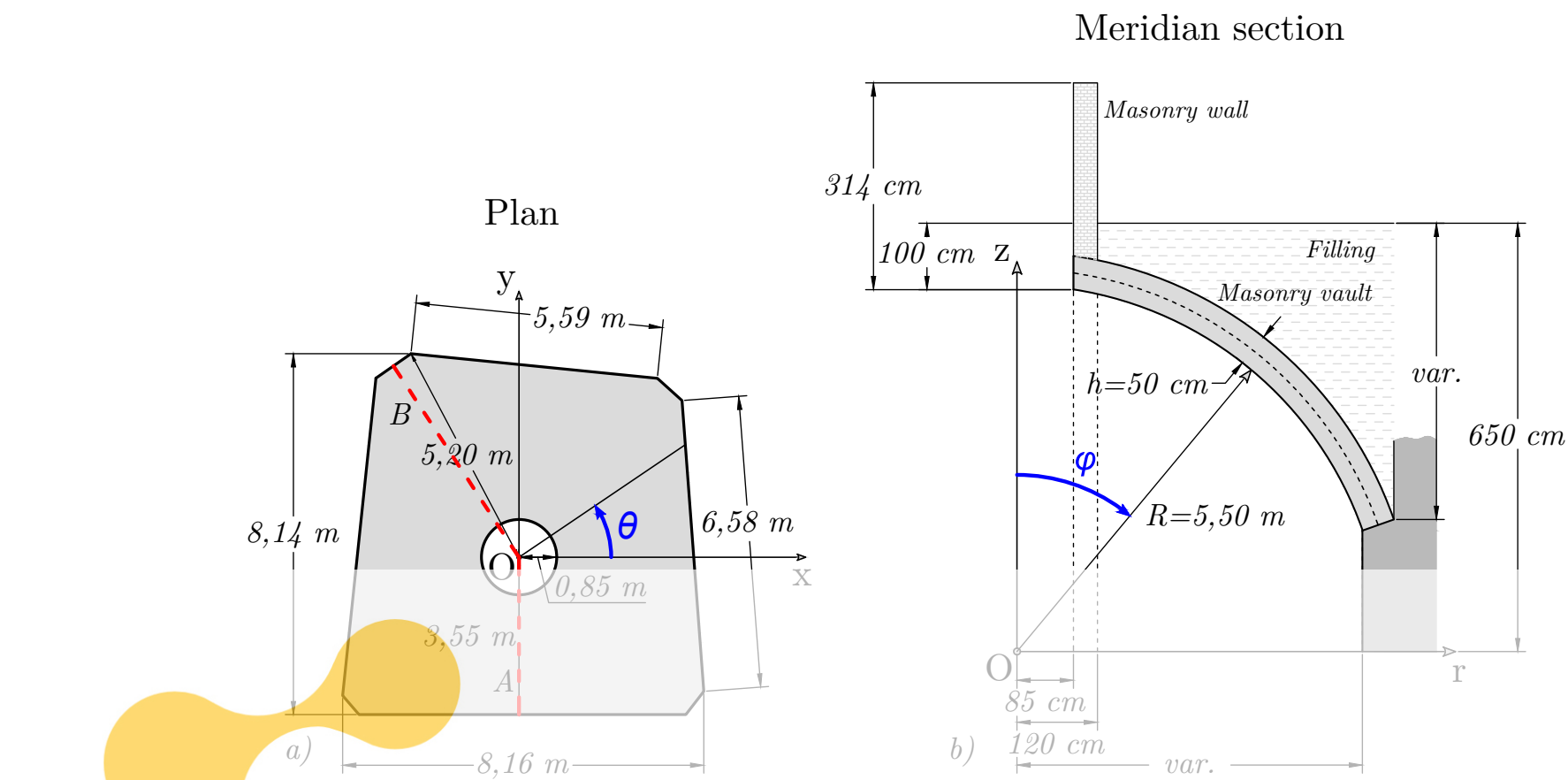

Figure 2: Geometry of the vault: plan (left) and vertical section along a meridian (right).
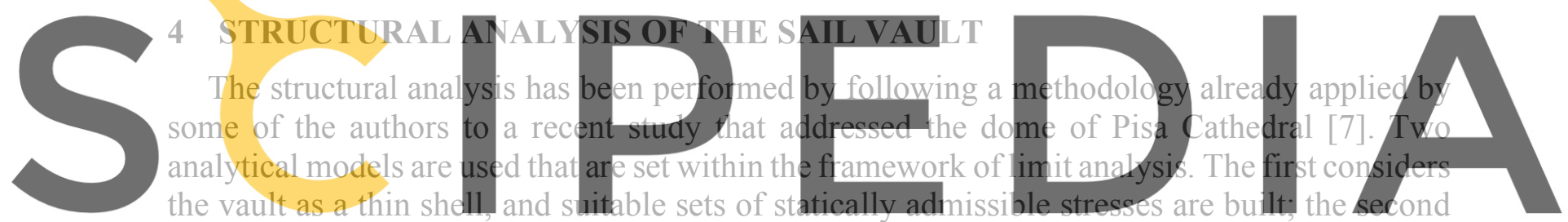

model is a modern reinterpretation of Durand-Claye's method for domes.

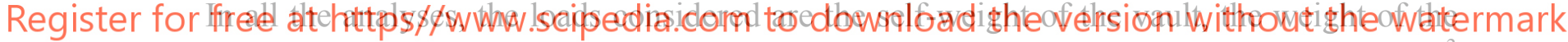

filling material and that of the masonry wall around the oculus. A specific weight of $18 \mathrm{kN} / \mathrm{m}^{3}$

has been adopted for the masonry and filling. By hypotheses, the walls are considered to be perfect constraints for the vault.

Structural analysis of the sail vault against the vertical loads represents just a first preliminary step toward the evaluation of the vault safety level. The vault as well as the whole Fortezza is a massive masonry construction built for defensive reasons; hence, no structural problem is to be expected as far as vertical loads are concerned. In the following some preliminary results are illustrated obtained by considering the effect of vertical loads. The effect of more severe actions such as internal explosions, bombing and cannon shots from enemy ships will be considered in the next phase of the research.

\subsection{Modeling the vault as a masonry shell: statically admissible internal forces distributions}

The analysis is aimed at determining statically admissible stress fields within the vault, which is modelled as a masonry shell. For the sake of simplicity, we limit the analysis to axialsymmetric distributions. In order to provide a first estimation of the safety level of the vault, 
two different safety factors may be introduced: the geometrical and mechanical safety factors. When geometrical safety factor is considered, the masonry compressive strength is assumed to be unbounded, and safety becomes a matter of geometry. The geometrical safety factor is defined as the ratio between the actual thickness of the vault and the minimum thickness for which it is possible to find a statically admissible stress field. When the mechanical safety factor is considered, the masonry's compressive strength is taken into account. The mechanical safety factor is defined as the ratio between the masonry compressive strength and the maximum stress in the vault.

Since the sail vault at hand is of considerable thickness, the geometric safety factor for vertical loads turns out to be very high. The calculations performed, which are not shown here for the sake of brevity, enable estimating a geometric safety factor of at least 40 .

As per the mechanical safety factor, a statically admissible distribution of the internal forces within the masonry shell is built by allowing bending stresses along the whole meridian and compressive hoop forces in the parallels near the top of the vault, within a region of given width (Figure 3). By optimizing the width of the region in which compressive hoop forces are present, the masonry strength assuring a mechanical safety factor of 3 can be made as low as $0.98 \mathrm{MPa}$.
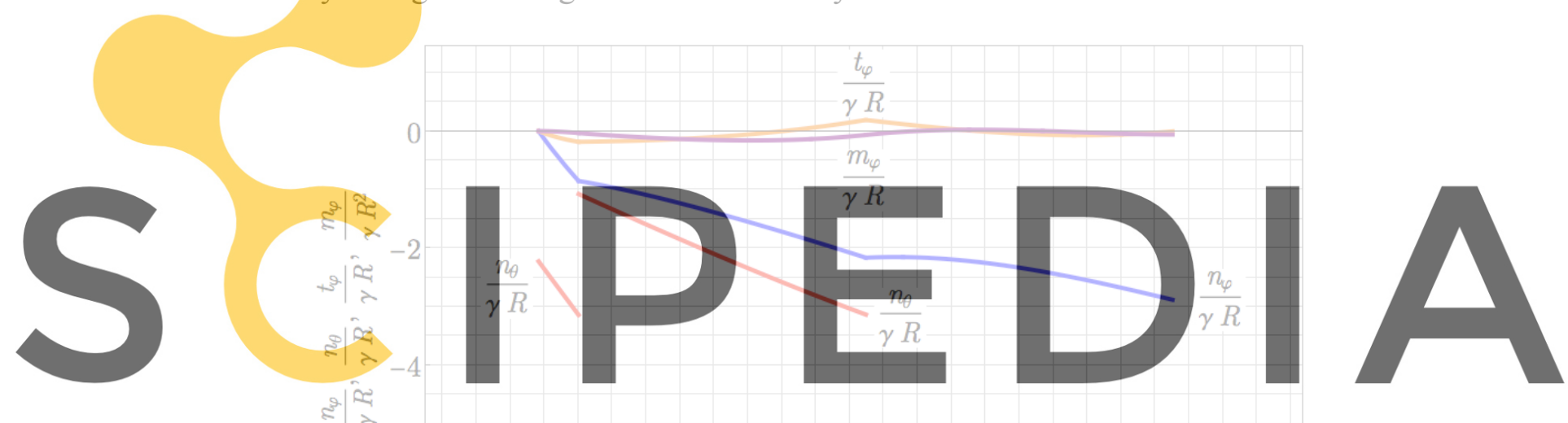

or free at https//www.scipedia.com to download the version without the watermark

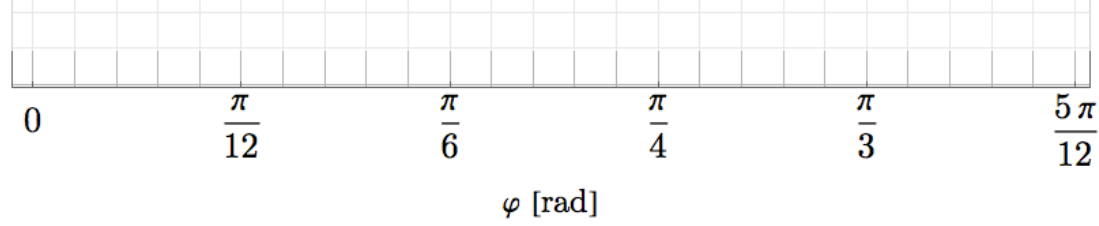

Figure 3: Dimensionless forces per unit length, $\left(n_{\theta}, n_{\varphi}=\right.$ axial force in parallels and meridians; $t_{\varphi}, m_{\varphi}=$ shear and bending moment in the meridians).

\subsection{Equilibrium analysis of the sail vault through a modern re-edition of Durand Claye's method}

In this section a revised version of Durand-Claye's method $[8,9]$ will be applied in order to perform a first evaluation of the stability of the sail vault. In previous papers, the authors have proposed a modern version of Durand-Claye's method by translating the complex graphical construction into a suitable set of equations in terms of the internal forces [10]. Furthermore, the method has been re-edited for domes in order to adequately take into account the influence 
of hoop forces and some kinematic aspects at collapse [11-12].

As illustrated more in detail in [2], a first equilibrium assessment can be conducted by applying the slicing technique. In this regard, Durand-Claye's method is applied to two lunes of embrace angle equal to $\varphi=40.11^{\circ}$ and $\varphi=70.79^{\circ}$, corresponding respectively to the dashed lines A and B in Figure 2, left. An infinite compressive strength is considered for the masonry. The top region near the central oculus is considered to be a rigid annulus of infinite strength. The red and blue curves in Figure 4 correspond to the attainment of a positive or negative limit bending moment at some joint in the radial direction: the stability area is the hatched area bounded by the aforementioned limit curves. Using the same notation adopted in [10-13], it is defined as the locus of the points $(P, e)$ corresponding to statically admissible solutions under the hypothesis of nil hoop forces. Since both stability areas in Figure 4 are extended, the lunes under examination are in equilibrium even if compressive hoop forces are assumed to be nil. The thrust lines corresponding to the maximum (points B, D) and minimum (points A, C) values of the horizontal thrust $P$ are shown in Figure 5. Coherently with the stability area results, they are all contained within the lune's thickness.

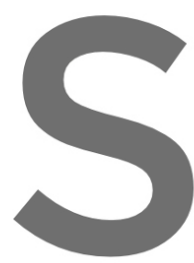

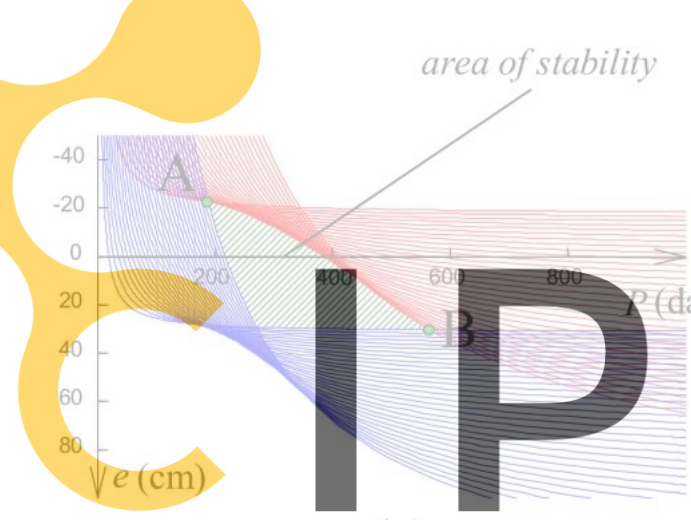

(a)

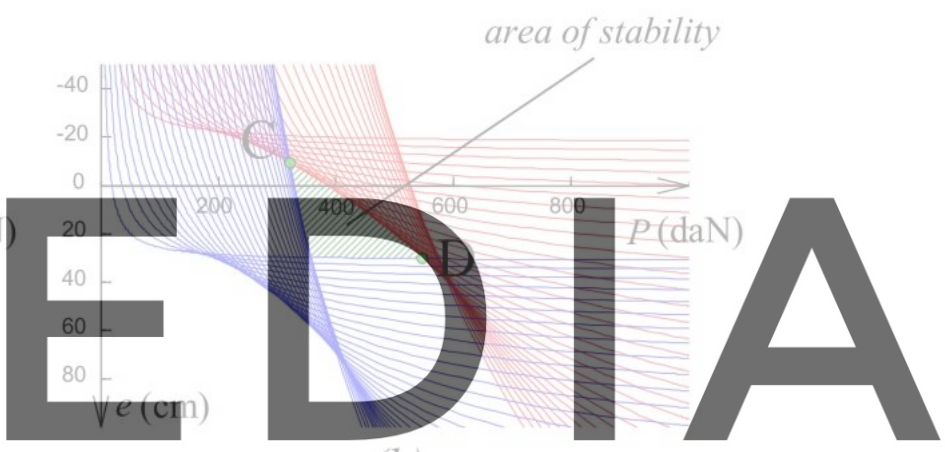

(b)

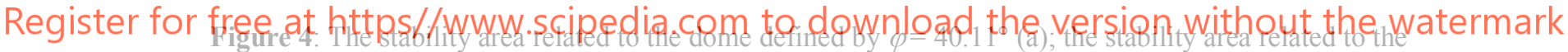
pendentive of maximum embrace angle $\varphi=70.79^{\circ}$ (b).

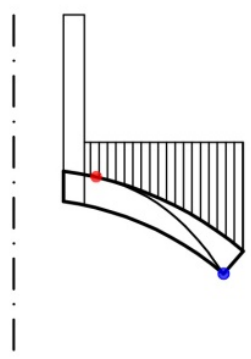

(Point A)

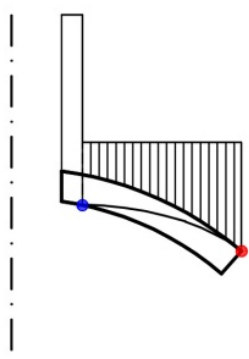

(Point B)

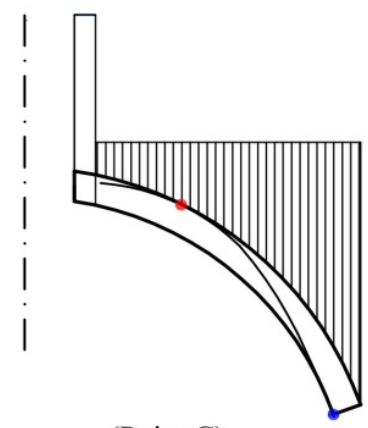

(Point C)

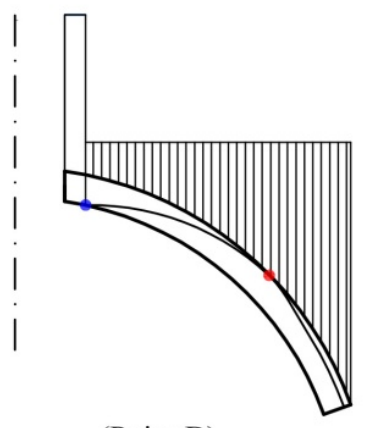

(Point D)

Figure 5: The maximum and minimum thrust lines related to points A, B, C, and D of the stability areas plotted in Figure 4. 
As expected, the Fortezza Vecchia sail vault is quite far from any collapse condition. Moreover, even if the stability area were reduced to a single point by progressively reducing the lune's thickness, this would not lead to a limit condition, since the collapse mechanism identified by the vanishing of the stability area would not be a kinematically admissible mechanism for the dome considered as a whole. In this case, the lateral surfaces of each lune would act as constraints by preventing inwards motion.

\section{CONCLUSIONS}

- $\quad$ The present contribution illustrates some first results of an ongoing research project aimed at studying the structural behavior of the subterranean brick masonry sail vault covering a trapezoidal room in the "Canaviglia" bastion in the Livorno "Fortezza Vecchia". The interdisciplinary analysis aims to take into account historical, geometrical, mechanical and construction aspects.

A detailed survey of the intrados surface has been carried out by means of a rangebased (laser scanning) survey methodology. A post-processing procedure has been adopted in order to obtain the vault's intrados sections in CAD format and the analytically determined 'best' approximating smooth surface.

Structural analysis of the vault has been performed by means of two different models set within the framework of limit analysis. The first model yielded a preliminary estimate of both the geometrical and mechanical safety factor by considering the
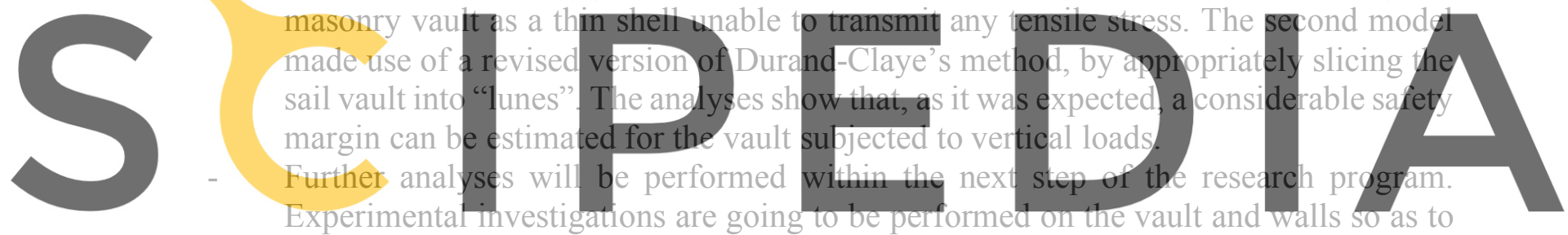

fully determine their main geometrical and mechanical parameters. Further study will

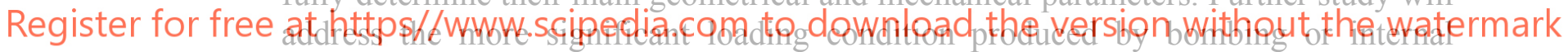

explosion by also taking into fully account the three-dimensional structural behavior of the sail vauit.

Acknowledgements. Financial support from the University of Pisa under programme PRA 2017, project "Architetture toscane rinascimentali: casi studio fra indagine storica, rilievo e analisi strutturale" is gratefully acknowledged. The collaboration of the Port System Authority of the Northern Tyrrhenian Sea is gratefully acknowledged.

\section{AUTHOR CONTRIBUTIONS}

I. FB, RB, SB; II. DU; III. FB, RB, DU, SB; IV. FB, DA, RB, SB; V. FB, DA, RB, DU, SB.

\section{REFERENCES}

[1] Barsi, F., Barsotti, R. and Bennati, S. Equilibrium of masonry sail vaults: the case study of a subterranean vault by Antonio da Sangallo the elder in the "Fortezza Vecchia" in Livorno. Submitted to the XXIV AIMETA Conf., Rome, Italy, 15-19 September 2019.

[2] Aita, D., Barsotti, R. and Bennati, S. Equilibrium analysis of a sail vault in Livorno's 
Fortezza Vecchia through a modern re-edition of the stability area method. Submitted to the XXIV AIMETA Conf., Rome, Italy, 15-19 September 2019.

[3] Frattarelli Fischer, L. L'Arcano del mare - Un porto nella prima età globale: Livorno. Pisa (2018).

[4] Vasari, G. Le vite de' più eccellenti architetti, pittori, et scultori italiani, da Cimabue insino a' tempi nostri. Firenze: Lorenzo Torrentino (1550).

[5] Ulivieri, D. Fortezza Vecchia in Livorno. Nexus Network J. (2014) 16 (3):675-697.

[6] Bevilacqua, M.G., Caroti, G., Piemonte, A. and Ulivieri, D. Reconstruction of lost architectural volumes by integration of photogrammetry from archive imagery with 3-D models of the status quo. Int. Arch. Photogramm. Remote Sens. Spatial Inf. Sci., XLII2/W9, 119-125, DOI 10.5194/isprs-archives-XLII-2-W9-119-2019 (2019).

[7] Bennati, S., Aita, D., Barsotti, R., Caroti, G., Chellini, G., Piemonte, A., Barsi, F. and Traverso, C., (in press), Survey, experimental tests and mechanical modeling of the dome of Pisa Cathedral: a multidisciplinary study. International Journal of Masonry Research and Innovation.

[8] Durand-Claye, A. Note sur la vérification de la stabilité des voûtes en maçonnerie et sur l'emploi des courbes de pression. Ann. des Ponts et Chaussées (1867) 13:63-93.

[9] Durand-Claye, A. Vérification de la stabilité des voûtes et des arcs. Applications aux voûtes sphériques. Ann. des Ponts et Chaussées (1880) 19 I sem.:416-440.

[10] Aita, D., Barsotti, R. and Bennati, S. A modern reinterpretation of Durand-Claye's method

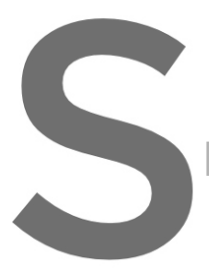
for the study of Salerno, L. Ascione, V. Edizioni, Mediglia (MI),

[11] Aita, D., Barsotti, R masonry arches thrt Applied Mechanics (2019)
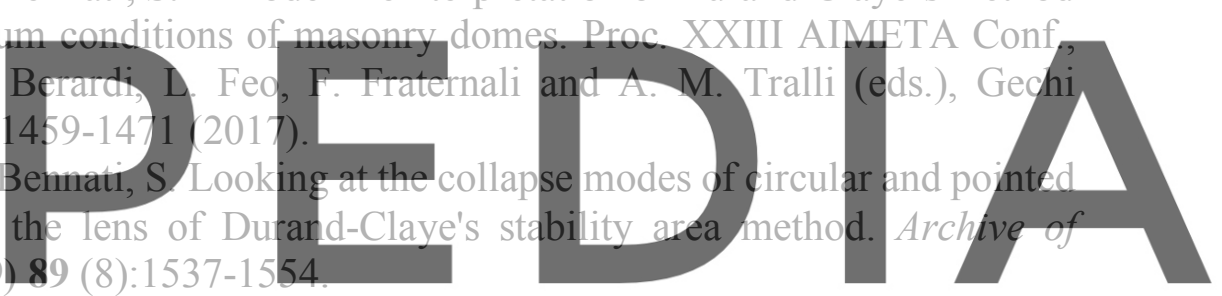

[12] Aita, D., Barsotti, R. and Bennati, S. A parametric study of masonry domes equilibrium

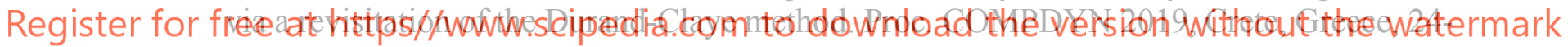
26 June 2019, M. Papadrakakis, M. Fragiadakis (eds.) (2019).

[13] Aita, D., Barsotti, R., Bennati S. Studying the dome of Pisa cathedral via a modern reinterpretation of Durand-Claye's method, JoMMS (2019) 14(5): 603-619, DOI: 10.2140/jomms.2019.14.603. 